\title{
Influence of the cold work effects in perforated rack columns under pure compression load
}

\author{
J. Bonada ${ }^{*}$, M.M. Pastor, F. Roure, M. Casafont \\ Department of Strength of Materials and Structural Engineering \\ Escola Tècnica Superior d'Enginyeria Industrial de Barcelona (ETSEIB) \\ Universitat Politècnica de Catalunya (UPC) \\ Av. Diagonal, 647, 08028 Barcelona, Spain
}

\begin{abstract}
This paper analyses the influence of residual stresses and strain hardening due to the cold rollforming process on the load carrying capacity of perforated rack columns. First of all, a residual strain distribution of the manufacturing process is obtained via a finite element analysis and then it is introduced in the model as initial state to carry out a nonlinear buckling analysis. Two different methodologies to introduce the residual strain pattern are presented in order to reproduce the local stress effects because of perforations. Moreover, the changes of the mechanical properties of the material by strain hardening are evaluated through experimental tests and its influence on the rack column behaviour is investigated. The results obtained agree well with experimental tests and show a method to predict the load carrying capacity of perforated rack column taking into account the effects of the cold roll-forming process.
\end{abstract}

Keywords: Rack column; residual stresses; strain hardening; FE analysis.

*Corresponding author. Tel.: +34 93 4016226; fax: +34 934011034.

E-mail addresses: jordi.bonada@upc.edu (J. Bonada), m.magdalena.pastor@upc.edu (M.M. Pastor), francesc.roure@upc.edu (F. Roure), miquel.casafont@upc.edu (M. Casafont) 


\section{Introduction}

In order to analyse the structural behaviour of rack columns under pure compression load, a finite element model including geometric and material nonlinearities is usually done [1-5].

An arbitrary geometric imperfection is commonly introduced to carry out a nonlinear buckling analysis of a rack member. This initial geometric imperfection includes the effect of the real geometric imperfection, the influence of cold work effects, possible loading eccentricity, etc. As a consequence, the magnitude and the shape of the geometrical imperfection modelled in the numerical analysis do not always match with experimental measurements.

Many investigations are focused on the influence of the magnitude and the shape of the initial geometric imperfection in the structural behaviour of thin-walled members. The magnitude depends on the type of the predominant mode of failure, global, local or distortional buckling. Moreover, for each type of failure mode, different values of magnitudes can be found in references [6-8]. Pastor et al [9] analysed the influence of the imperfection magnitude in the load carrying capacity of a rack column. The conventional numerical analysis uses a buckling mode to define the geometrical imperfection, but the type of the dominant mode of the buckling shape used for the nonlinear analysis is a key factor to obtain accurate results [10-11].

The influence of residual stresses on the load carrying capacity of thin-walled sections has been analysed in several papers. Quach et al [12] introduced the residual stresses of a press-braked Csection [13-16] in a nonlinear buckling analysis. In [17] an analysis to predict the load carrying capacity of non-perforated rack columns was presented considering the residual stresses due the cold roll-forming process obtained through finite element analysis of the manufacturing process. If the methodology presented in [17] is used, it is not necessary to define an arbitrary initial geometric imperfection in order to calculate the ultimate load of rack columns under pure compression load.

It is well known that cold forming process can enhance the mechanical properties of the material. The yield strength and the ultimate tensile strength may increase because of strain hardening. Karren and Winter [18] analysed and developed several theoretical models to calculate the strength enhancement in corner areas of cold-formed thin-walled sections. Crisan et al [19] analysed the changes of the yield strength and the ultimate strength in corner and flat areas of rack sections. The results showed that corner coupons presented an increase of the yield strength and the ultimate strength, whereas the changes of mechanical properties in flat regions were insignificant. The experimental set-up to conduct the tensile tests of corner coupons is 
more complex than for flat coupons in order to avoid the bending stresses during the test [2021].

The main goal of this paper is to analyse the influence of the residual stresses and the strain hardening due to the cold roll-forming process on the load carrying capacity of perforated rack columns under pure compression load.

\section{Material properties}

The analysed rack section is shown in Fig 1. During the cold roll-forming process, several parts of the steel sheet are plastically deformed to obtain the final shape. As a consequence, the mechanical properties of the material in some areas may change.

First of all, in order to determine the enhancement of the mechanical properties of the material, several coupons were cut out from parts of the cross-section (Fig 2) and from the virgin sheet coil as well.

Table 1 shows the values of the tensile tests done from the virgin sheet coil and from flange 1 , flange 2 and web coupons of a non-perforated rack upright following the recommendations of EN10002-1 European Standard. The results indicate that the yield and the ultimate strength do not significantly increase as a consequence of the cold roll-forming process. As a result, the changes of the mechanical properties of the material in the flat areas can be neglected.

Secondly, nine coupons were cut out from a perforated rack upright, three coupons from the only flat area without any perforation (flange 1 ) and the others from the corner defined by the web and the flange (Fig 2). The increase of the mechanical properties in the corner areas of the rack section is analysed by means of these coupons.

In order to do the tensile tests of the corner coupons a specific set-up has been designed to avoid flattening the ends and applying the axial force in the centre of gravity of the corner coupons. The set-up (Fig 3-4) allows the right alignment of the coupons and it avoids the influence of the bending stresses.

Table 2, Fig 5 and 6 show the results of the experimental tensile tests of the corner and the flat (flange 1) coupons cut out from a perforated rack upright (engineering curves). The values of the yield and the ultimate strength in the corner areas are $17.5 \%$ and $7.7 \%$ higher than in the flat 
areas, respectively because of strain hardening. Moreover, it can be observed that ductility in the corner areas has been decreased from $25 \%$ to $11 \%$ or less (Fig 6).

The experimental measurements of the yield strength of the corner coupons have been compared with the second theoretical model presented by Karren and Winter in [18], the European standard EC3-Part 1-3 [22] (Eq 1) and the American standard AISI S100-2007 [23] (Eq 2). In order to apply the theoretical model of Karren and Winter (Eq 3) a Swift's model law for the true stress-strain relationship has been adjusted (Eq 4). In spite of the experimental results are lower than the analytical models, the results obtained are consistent as it is shown in Table 3.

$$
\begin{aligned}
& f_{y a}=f_{y}+\left(f_{u}-f_{y}\right) \frac{k \cdot n^{90} \cdot t^{2}}{A} \\
& f_{y a}=\frac{f_{y, \text { flat }} \cdot A_{\text {flat }}+f_{y, \text { corner }} \cdot A_{\text {corner }}}{A}
\end{aligned}
$$

$$
\begin{aligned}
& f_{y, \text { corner }}=\frac{B_{c} \cdot F_{y v}}{\left(\frac{R}{t}\right)^{m}} \\
& B_{c}=3.69 \frac{F_{u v}}{F_{y v}}-0.819\left(\frac{F_{u v}}{F_{y v}}\right)^{2}-1.79 \\
& m=0.192\left(\frac{F_{u v}}{F_{y v}}\right)-0.068 \\
& f_{y, \text { corner }}=\frac{K}{b-a} \int_{a}^{b}\left|\frac{2}{\sqrt{3}} \ln \left(\frac{r}{\sqrt{a \cdot b}}\right)\right|^{n} \cdot \frac{r}{\sqrt{a \cdot b}} d r \\
& \sigma=780 \cdot\left(\varepsilon_{p}+0.044\right)^{0.2}
\end{aligned}
$$

It is well known that the enhanced corner strength value can also be calculated by finite element analysis of the manufacturing process [12, 24-25]. The equivalent plastic strains of corner areas because of the manufacturing process can be obtained from the FEA explained at Section 3 . The 
average equivalent plastic strain value obtained in corner areas is 0.0744. Therefore, the increased yield strength numerically obtained is around $509 \mathrm{MPa}$. This value agrees well with all the models compared in Table 3.

\section{Finite element analysis}

\subsection{Cold roll-forming process}

The residual stresses of the rack member due to the cold roll-forming process are calculated by a finite element analysis done in COPRA FEA RF software. The residual stress distribution obtained does not consider the punching operation, coiling and uncoiling of the virgin sheet coil. The main features of the simulation are the following ones:

(i) The roll-forming line consists of 22 rolling stands. The stand spacing is between 80 (idler roll stands) and $450 \mathrm{~mm}$.

(ii) The steel sheet (length of $1500 \mathrm{~mm}$ ) is meshed with brick (8 nodes) elements. The rollers are meshed with rigid shell elements (Fig 7). The friction between sheet and rolls has been neglected. In the numerical simulation, the forming rolls are passed and the steel sheet remains stationary.

(iii) A Swift's curve is used to define the plastic behaviour of the sheet material. The curve is adjusted to the entire true stress-true strain curve of the virgin sheet coil experimentally obtained (Eq 4).

(iv) Only a half of the sheet is modelled because of the symmetry.

(v) A total of 20551 elements are used to mesh the steel sheet (Fig 8).

(vi) A geometric and material nonlinear analysis is done. The CPU time required for the simulation is around 575 hours (Intel Core Quad CPU 2.83GHz).

The roll-forming line has been modified until the desired shape is obtained. The overbend of the flange has been adjusted to compensate the springback effect $\left(1^{\circ}\right)$. Nevertheless, a small geometric imperfection is generated because of the cold roll-forming process. This imperfection has not been considered for the nonlinear buckling analysis.

When a nonlinear analysis is carried out, the cold work effects numerically obtained could be different depending of the hardening plasticity law used [26]. For this case, an isotropic hardening model has been employed in the FE analysis because in several experimental research studies [18] the same strength enhancement in tension and compression corner coupons have 
been obtained on a thin walled cold-roll formed steel section. However, the influence of the type of plasticity hardening law employed in FE analysis is not evaluated in this paper.

\subsection{Nonlinear buckling analysis}

The finite element model for the nonlinear buckling analysis has been created by using ANSYS code. The analysis uses the element type SOLID 186 (20-node brick element). The model includes the enhancement of the mechanical properties in the corner areas and the residual stresses induced during the roll-forming process as initial state.

In order to reproduce the strength enhancement in the corner areas of the cross-section two different materials have been defined to mesh the rack column. Both materials use the same Young's modulus and Poisson's ratio, but different yield strength and plastic stress-strain relationship are defined. The flat areas have the same properties as the virgin sheet coil (Table 1) and the corner areas use the mechanical properties measured through the experimental tests in Section 2. It has been considered that the enhanced mechanical properties take effect only in the curved corner regions. Fig 9 shows the true stress-strain relationship for both cases.

The enhanced corner stress-strain behaviour could also be taken into account through the introduction of the equivalent plastic strain numerically obtained by COPRA FEA RF analysis. However, experimental tests have been done to evaluate the strain hardening because only one brick element is used to mesh the rack section in the thickness direction in order to reduce the computational cost of numerical simulations.

In order to predict the ultimate load of the rack column, the nonlinear buckling analysis takes into account the residual stresses due to cold roll-forming process. The residual elastic and plastic strains (not the equivalent plastic strain) obtained by COPRA FEA RF simulation are introduced as initial state in the ANSYS analysis. The simplified methodology defined in [17] is used to carry out the data transfer from COPRA FEA RF to ANSYS. In [17] a residual strain pattern can be easily defined because the rack upright do not has any perforation. For perforated columns two different methods are developed to define the residual strain pattern. The main steps for the data transfer are: (i) Selection of a finite element of the rack upright. (ii) Calculation of the S-coordinate (defined along the mid-lane of half cross-section) for all nodes of the element. (iii) Separation of the nodes located at the outer and the inner face of the crosssection. (iv) Introduction of the residual elastic and plastic strains values in the eight integration points associated at the eight vertex nodes using the residual strain pattern obtained by COPRA FEA RF and linear interpolation functions. This process is repeated for all elements. 
Two different methods to define the initial state of a rack column are presented and the results obtained are compared with each other in Section 4.

\subsubsection{Definition of the initial state: Multi-pattern method}

The multi-pattern methodology tries to reproduce accurately the influence of perforations in the residual strain distribution. The pitch of the upright has been divided in three different zones (Z0, Z1 and Z2) as it is shown in Fig 10. Each zone has its own residual strain pattern. This methodology introduces the appropriate strain values in the integration point as a function of the zone where it is located.

The COPRA FEA RF finite element analysis shows six different zones (Zone A to F) where the residual strain distribution presents local effects because of perforations (Fig 11). Fig 12 proves that the multi-pattern methodology is able to reproduce these local effects along the column length and Fig 13 reveals that the developed data transfer works correctly.

\subsubsection{Definition of the initial state: Virtual pattern method}

The virtual pattern methodology uses a single residual strain pattern defined through a virtual path without any perforations. This virtual path is obtained by using two different cross-sections along the pitch length as it is shown in Fig 14. The first cross-section has the perforation in the web and it is used to define the virtual path from point $\mathrm{P}$ to $\mathrm{P}$ '. The second cross-section has the hole in the flange and it is used to define the virtual path from point $\mathrm{P}$ ' to $\mathrm{P}$ '’.

The residual strain pattern is calculated through the strain values of the virtual path and it is introduced and spread along the column length. Fig 15 shows the difference between the virtual pattern and the three different patterns used in the multi-pattern methodology. The virtual pattern method is faster to use than the multi-pattern method, but Fig 16 shows that only two different local effects in the residual strain distribution are correctly reproduced (Zone A and E). 


\section{Results}

The results obtained through the nonlinear buckling analysis are compared with the experimental tests done by the authors. Seven column lengths have been analysed. For each column length, three different samples have been tested. The experimental set-up used restrains the local distortion at each end of the rack column. The whole sample is pinned at both ends and a special device avoids the rotation around the longitudinal axis of the member. More details of the experimental tests can be found in [10].

\subsection{Influence of residual stresses}

First of all, the results obtained from the multi-pattern and virtual pattern methodology have been compared by considering only the effect of the residual strains and stresses in order to determinate the most efficient method. Table 4 and 5 show the results from the multi-pattern and virtual pattern method, respectively.

Both methodologies produce similar results. The main difference between them is the geometrical imperfection value generated due to the equilibrium of the residual strain distribution introduced as initial state into the finite element model, but its influence is insignificant if the residual stresses are used in the nonlinear buckling analysis [17]. This geometrical imperfection is obtained as a consequence of introducing a simplified strain pattern along the column length. The generated imperfection shape is very similar to a symmetrical distortional buckling mode. The results reveal that a good prediction of the load carrying capacity of perforated rack columns can be obtained through the introduction of the residual strain distribution. As a consequence, the virtual pattern methodology is used to analyse the influence of strain hardening.

\subsection{Influence of strain hardening}

Fig 17 illustrates the effect of including strain hardening in the FEA. The strength enhancement in the corner areas is only relevant for the shortest column length (250 mm), which is the only length showing a dominant local buckling failure mode.

Furthermore, the post-buckling behaviour of the rack column has also been analysed. Fig 18 shows the force-axial displacement corresponding to the finite element analysis and experimental results of the $250 \mathrm{~mm}$ column length. The comparison has been focused at the column length with the highest influence of the strain hardening (Fig 17). In spite of the small 
influence on the load carrying capacity, the post-buckling response of the column is different and more accurate to experimental measurements if the changes of the mechanical properties are considered.

\section{Conclusions}

A study of the influence of the cold-work effects in a rack column under pure compression load through experimental tests and finite element analysis has been presented.

First of all, the strain hardening effect due to the cold roll-forming process has been analysed. On the one hand, the yield strength and the ultimate strength have increased in corner areas and ductility has decreased. On the other hand, the changes in the mechanical properties of flat parts of the cross-section are irrelevant. Furthermore, the equations to calculate the increase of the yield strength in corner areas according to the European and the American Standard present similar values to the experimental tests and to FE values for this type of cross-section. However, the changes in the mechanical properties due to cold work depend on several parameters such as steel grades, corner radius, thickness of steel sheet, etc. Thus, the cold-work effects obtained may be only applicable to rack sections with similar parameters.

Two different methodologies have been developed in order to introduce the residual strain pattern of the roll-forming process as initial state for a further analysis. The use of the multipattern methodology allows a more accurate reproduction of the local strain effects around perforations. However, it is not necessary to achieve this level of accuracy in the residual strain pattern to obtain accurate results to predict the load carrying capacity of rack columns. The ultimate load can be correctly obtained by using a virtual path to define the residual strain pattern. The virtual pattern methodology predicts the ultimate load of rack columns without using any arbitrary geometrical imperfection obtained by a linear buckling analysis.

The strength enhancement in the corner areas only has a relevant influence at short column lengths where local buckling is the dominant failure mode. In this type of failure, several parts of the cross-section present an equivalent strain higher than the yield strain, so the increase of the yield strength in corner areas produces an increase of the load carrying capacity of the rack column. It also causes a different behaviour in the post-buckling response of the member. However, the influence of strain hardening, at the column lengths where the distortional or global buckling mode is dominant, is insignificant for the prediction of the ultimate load and small for the prediction of the post-buckling behaviour. 


\section{References}

[1] Schafer BW, Li Z, Moen CD. Computational modelling of cold-formed steel. Thin-Walled structures 2010; 48:752-762.

[2] Ashraf M, Gardner L, Nethercort DA. Finite element modelling of structural stainless steel crosssections. Thin-Walled Structures 2006; 44:1048-1062.

[3] Dubina D, Ungureanu V. Manual on numerical analysis of thin-walled cold-formed steel structures. ECCS TC7 Annual Meeting, Hämeenlinna Finland, June 25-26 2009.

[4] Bakker MCM, Peköz T. The finite element method for thin-walled members-basic principles. Thin-Walled Structures 2003; 41:179-189.

[5] Sarawit AT, Kim Y, Bakker MCM, Peköz T. The finite element method for thin walled membersapplications. Thin-Walled Structures 2003; 41:191-206.

[6] Schafer BW, Peköz T. Computational modelling of cold formed steel: characterizing geometric imperfections and residual stresses. Journal of Constructional Research 1998; 47: $193-210$

[7] Yap DCY, Hancock GJ. Interaction buckling and postbuckling in the distortional mode of thinwalled sections. Research Report No R870, The University of Sidney, April 2006.

[8] Chou SM, Chai GB, Ling L. Finite element technique for design of stub columns. ThinWalled Structures 2000; 37: 97-112.

[9] Pastor MM, Casafont M, Bonada J, Roure F. Imperfection amplitudes for nonlinear analysis of open thin-walled steel cross-sections used in rack column uprights. Thin-Walled Structures 2014; 76: 28-41.

[10] Bonada J, Casafont M, Roure F, Pastor M. Selection of the initial geometrical imperfection in nonlinear FE analysis of cold-formed steel rack columns. Thin-Walled Structures 2012; 51: 99-111. 
[11] Dubina D, Ungunreanu V. Effect of imperfections on numerical simulation of instability behaviour of cold-formed steel members. Thin-Walled Structures 2002; 40:239-262.

[12] Quach WM, Teng JG, Chung KF. Effect of the manufacturing process on the behaviour of press-braked thin-walled steel columns. Engineering Structures 2010; 32:3501-15.

[13] Quach WM, Teng JG, Chung KF. Residual stesses in steel sheets due to coiling and uncoiling: a closed-form analytical solution. Engineering Structures 2004; 26:1249-59.

[14] Quach WM, Teng JG, Chung KF. Finite element predictions of residual stresses in pressbraked thin-walled steel sections. Engineering Structures 2006; 28:1609-19.

[15] Quach WM, Teng JG, Chung KF. Residual stresses in press-braked stainless steel sections I: coiling and uncoling of sheets. Journal of Constructional Steel Research 2009; 65:1803-15.

[16] Quach WM, Teng JG, Chung KF. Residual stresses in press-braked stainless steel sections I: press-braking operations. Journal of Constructional Steel Research 2009; 65:1816-26.

[17] Pastor MM, Bonada J, Roure F, Casafont M. Residual stresses and initial imperfections in non-linear analysis. Engineering Structures 2013; 46:493-507.

[18] Karren, Winter. Effects of cold-forming on Light-gage steel members. Report 318. Department of Structural Engineering. School of Civil Engineering. Cornell University. 1965.

[19] Crisan A, Ungureanu V, Dubina D. Behaviour of cold-formed steel perforated sections in compression. Part I - Experimental investigations. Thin-Walled Structures 2012; 61:86-96.

[20] Guo YJ, Zhu Zhu A, Pi YL, Tin-Loi F. Experimental Study on compressive strengths of thickwalled cold-formed sections. Journal of Constructional Steel Research 2007; 63: 718-723.

[21] Zhu JH, Young B. Effects of transverse welds on aluminium alloy columns. Thin-walled Structures 2007; 47:321-329.

[22] EN 1993-1-3. Eurocode 3 - Design of steel structures - Part1-3: General rules Supplementary rules for cold-formed members and sheeting. September 2005. 
[23] AISI-S100-07. North American Specification for the Design of Col-Formed Steel Structural Members. 2007.

[24] Rossi B, Degée H, Boman R. Numerical simulation of the roll forming of thin-walled sections and evaluation of corner strength enhancement. Finite Elements in Analysis and Design 2013; 72:13-20.

[25] Quach WM, Qiu P. Strength and ductility of corner materials in cold-formed stainless steel sections. Thin-walled Structures 2014; 83:28-42.

[26] Gao T, Moen C. The cold work of forming effect in steel structural members. SDSS' Rio 2010 Stability and ductility of steel structures. September 2010. 


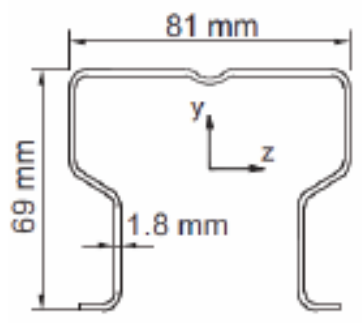

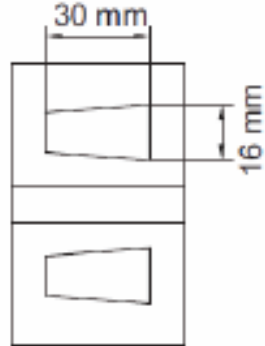

Web perforations

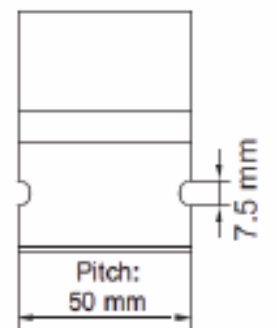

Flange perforations

Figure 1 - Geometrical dimensions of the analysed rack section

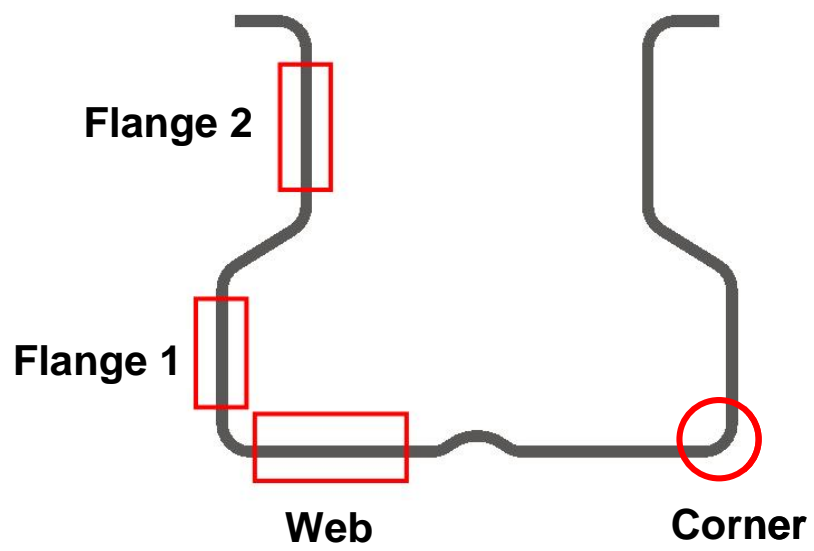

Figure 2 - Different zones of the cross-section where the coupons were cut out

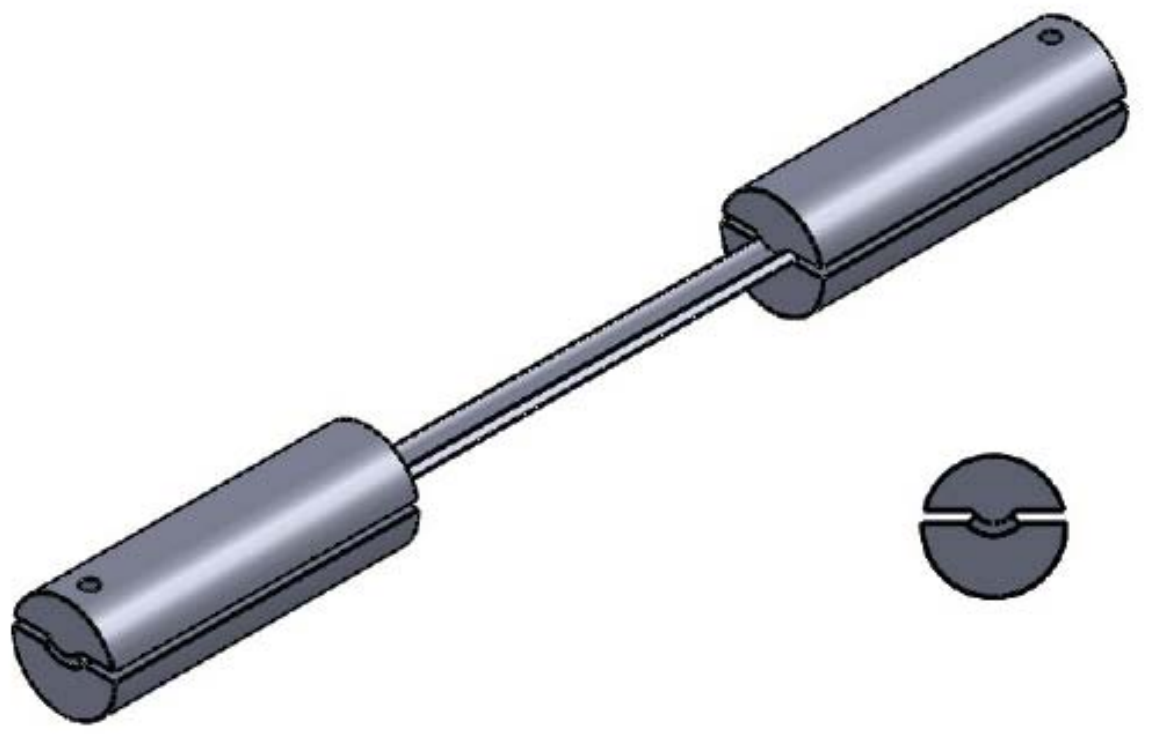

Figure 3 - Experimental set-up designed for the tensile test of corner coupons 


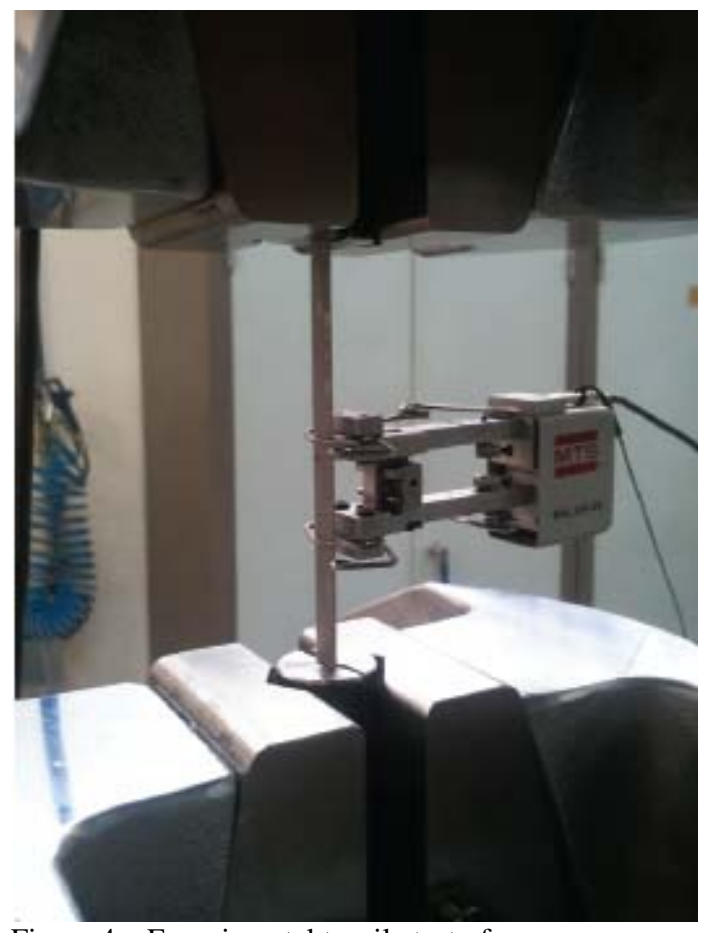

Figure 4 - Experimental tensile test of a corner coupon

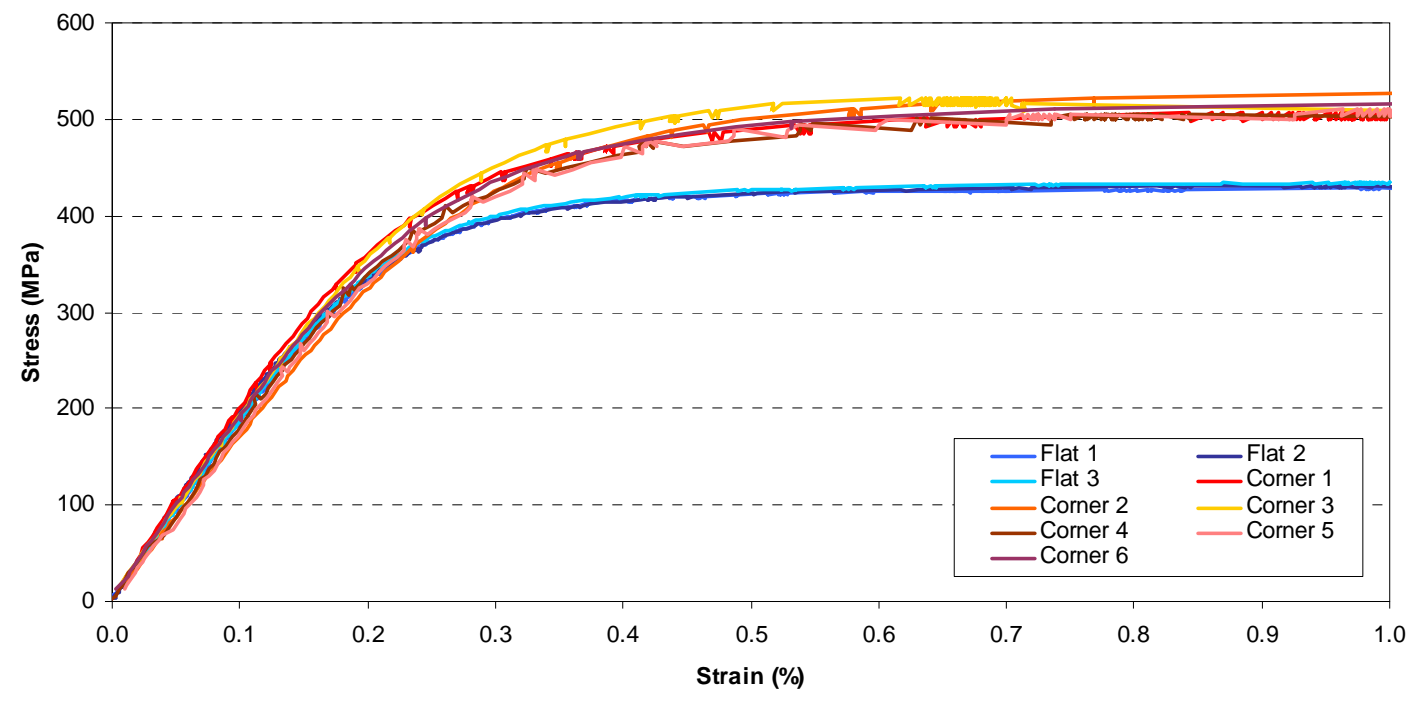

Figure 5 - Engineering stress-strain relationship of the tensile tests in the elastic range 


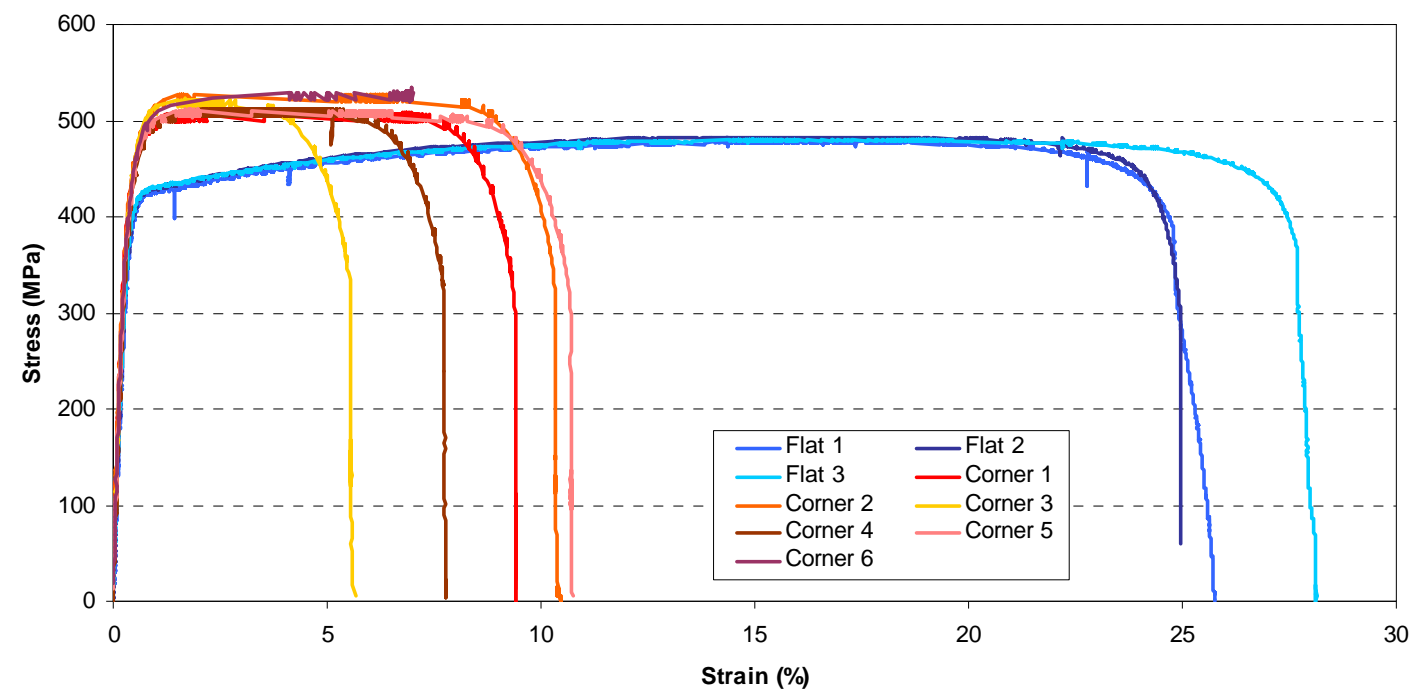

Figure 6 - Engineering stress-strain relationships of the tensile tests

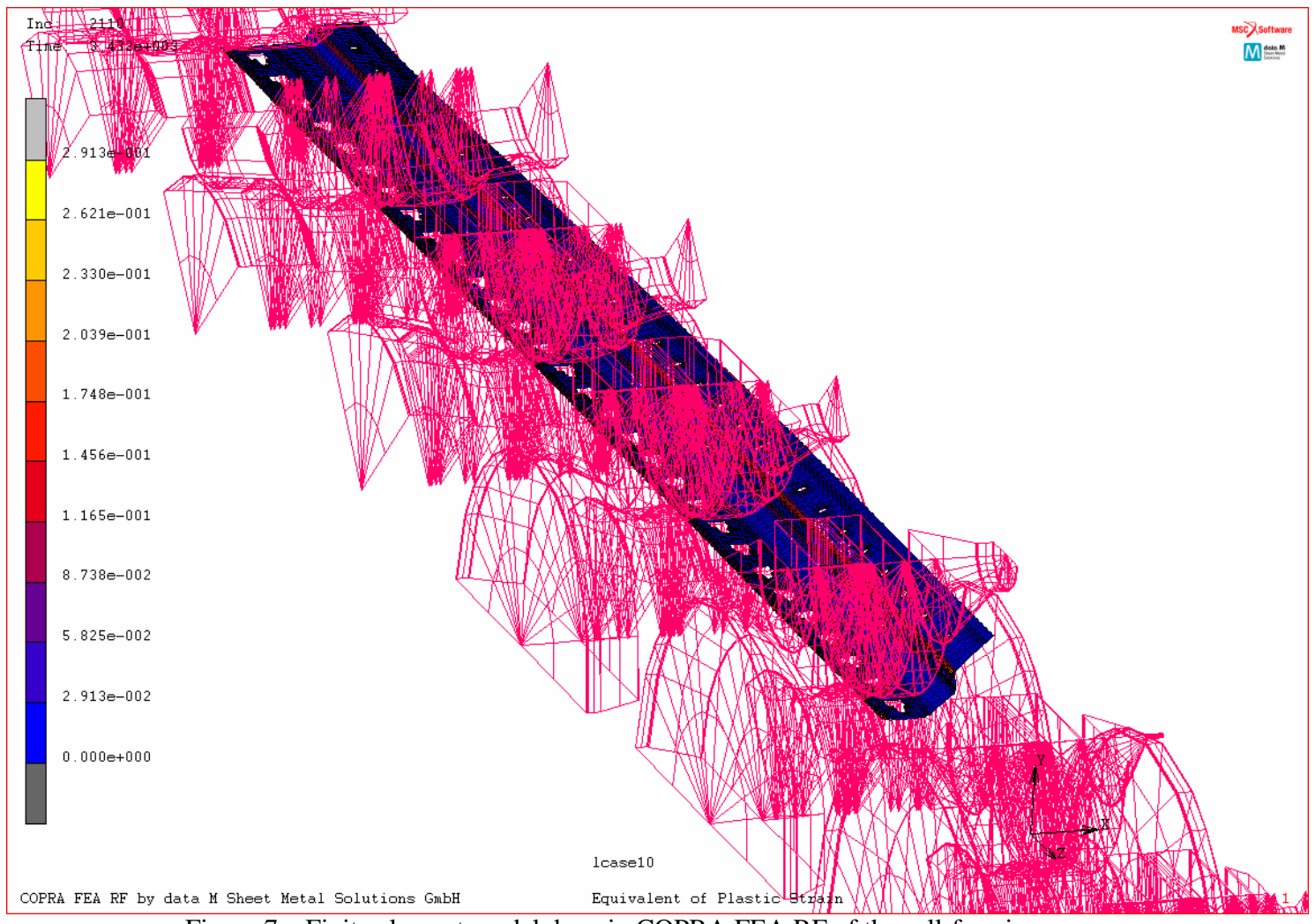

Figure 7 - Finite element model done in COPRA FEA RF of the roll-forming process 


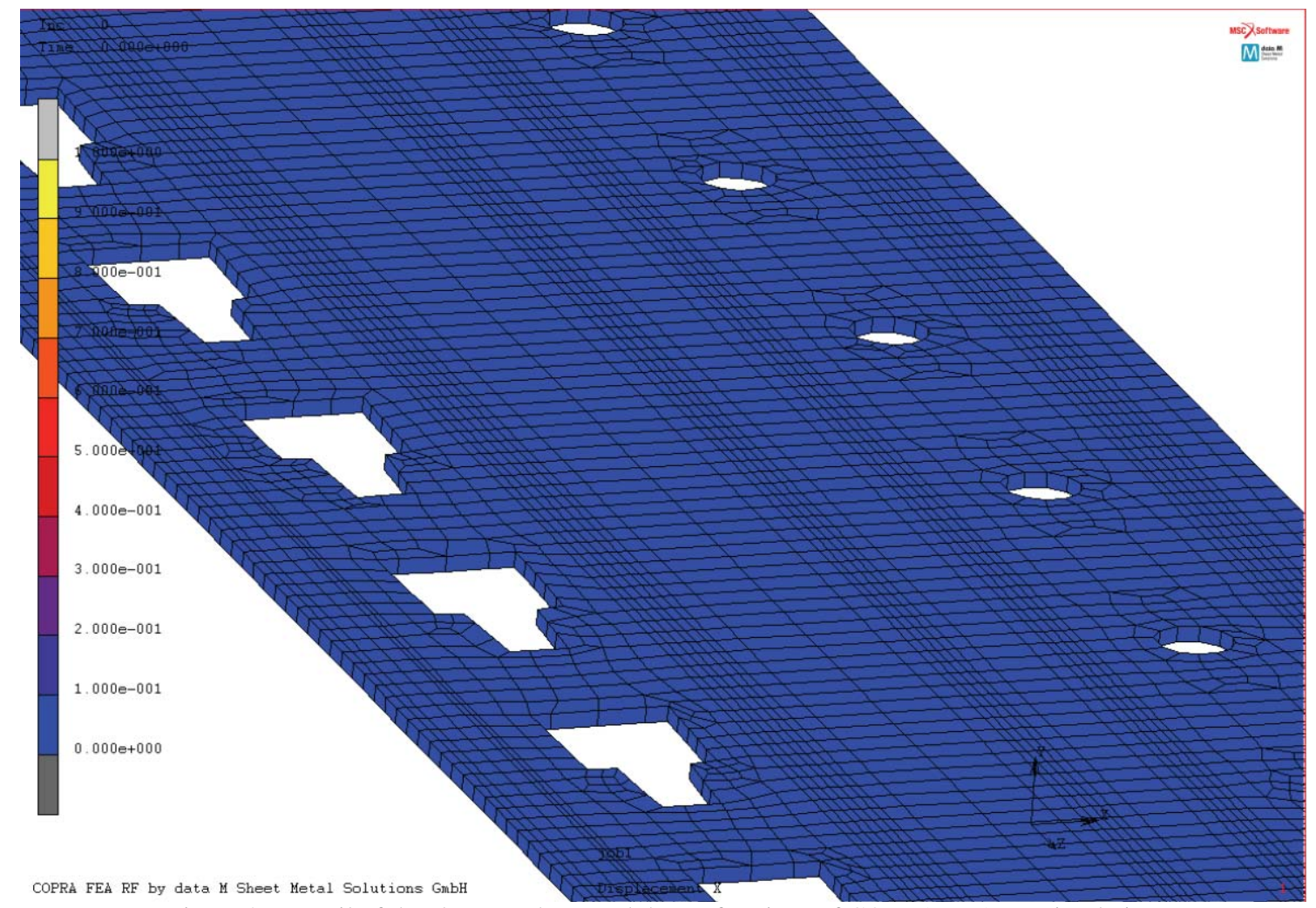

Figure 8 - Detail of the sheet mesh around the perforations of COPRA FEA RF simulation

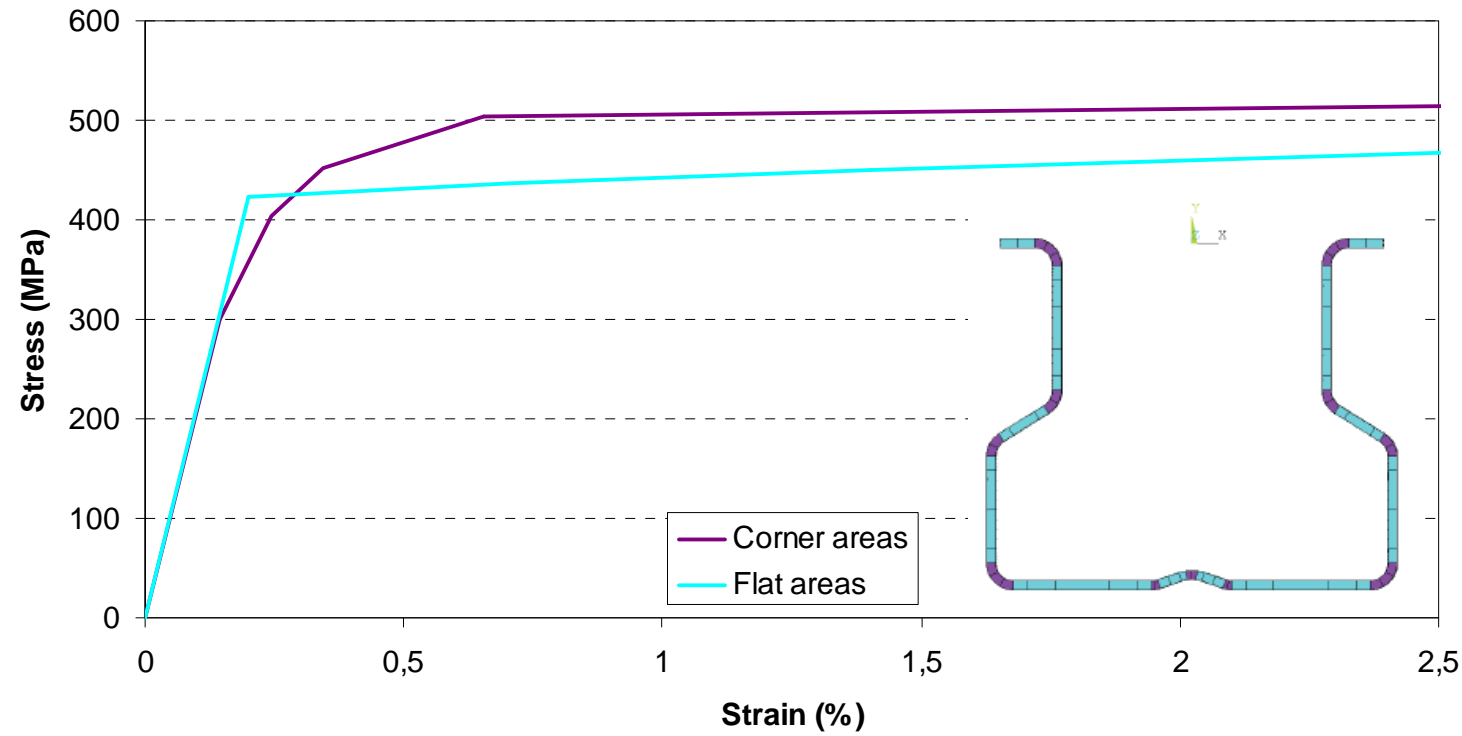

Figure 9 - True stress-true strain curve for the two different materials used to mesh the rack column 


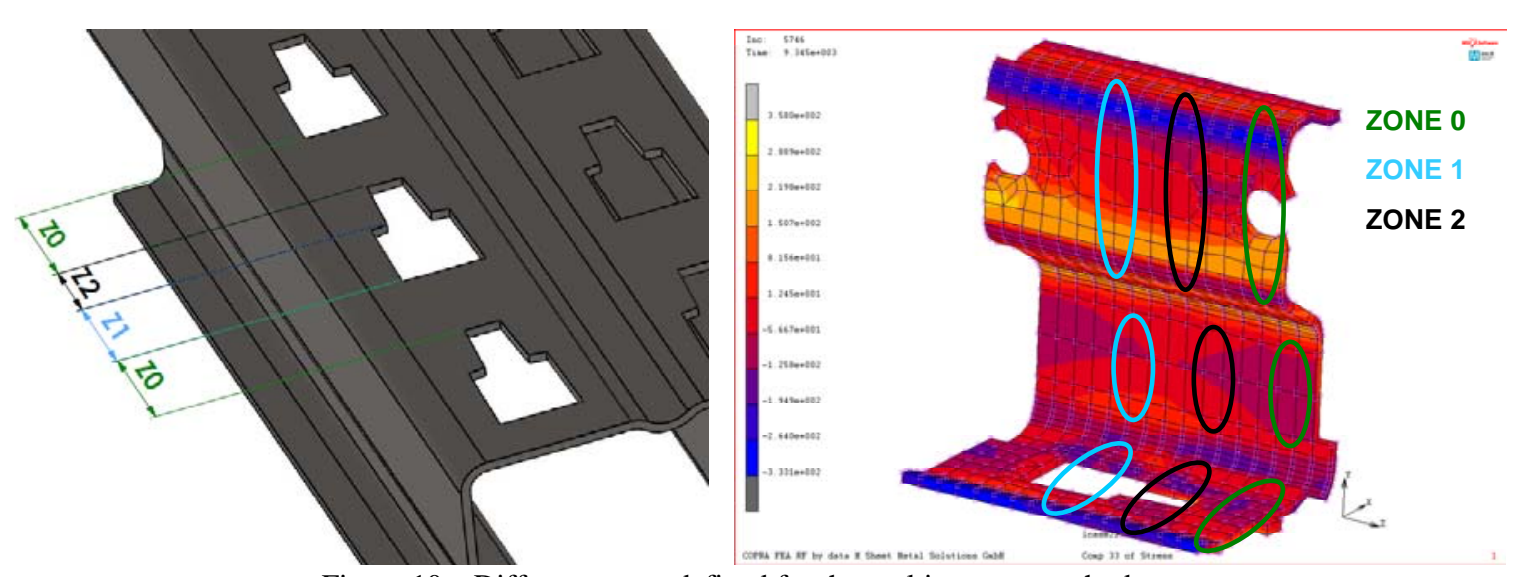

Figure 10 - Different zones defined for the multi-pattern method
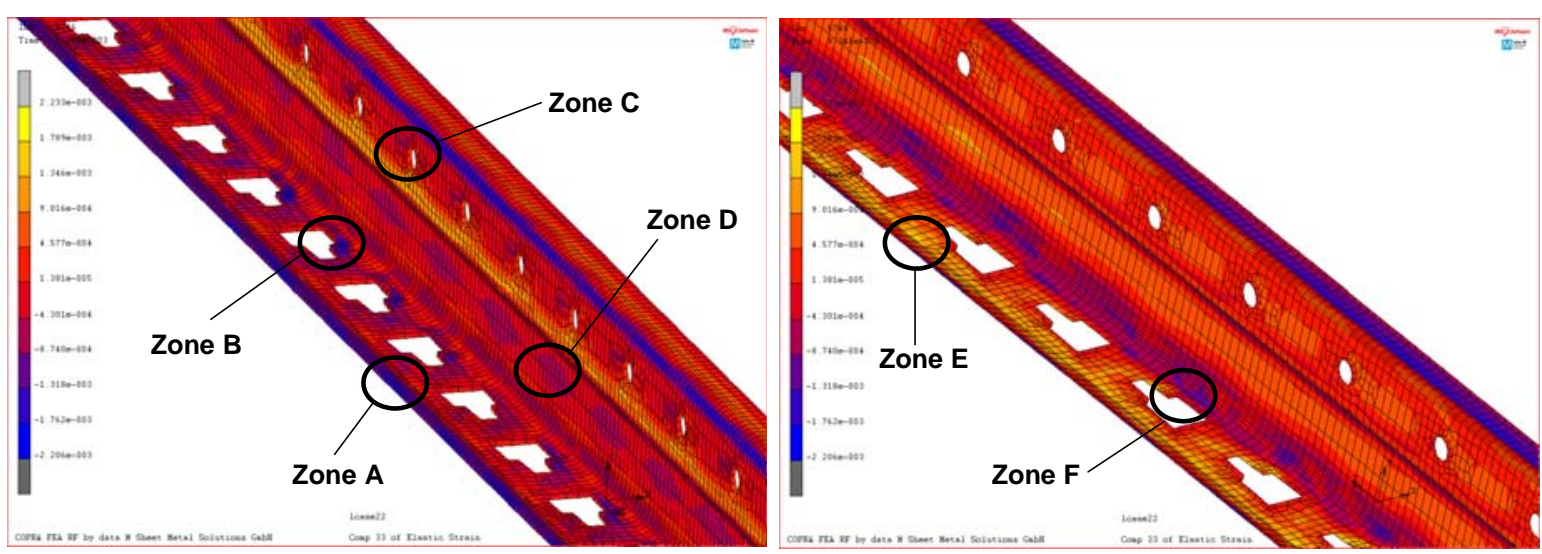

Figure 11 - Local effects in the residual longitudinal strain distribution obtained in COPRA FEA RF simulation
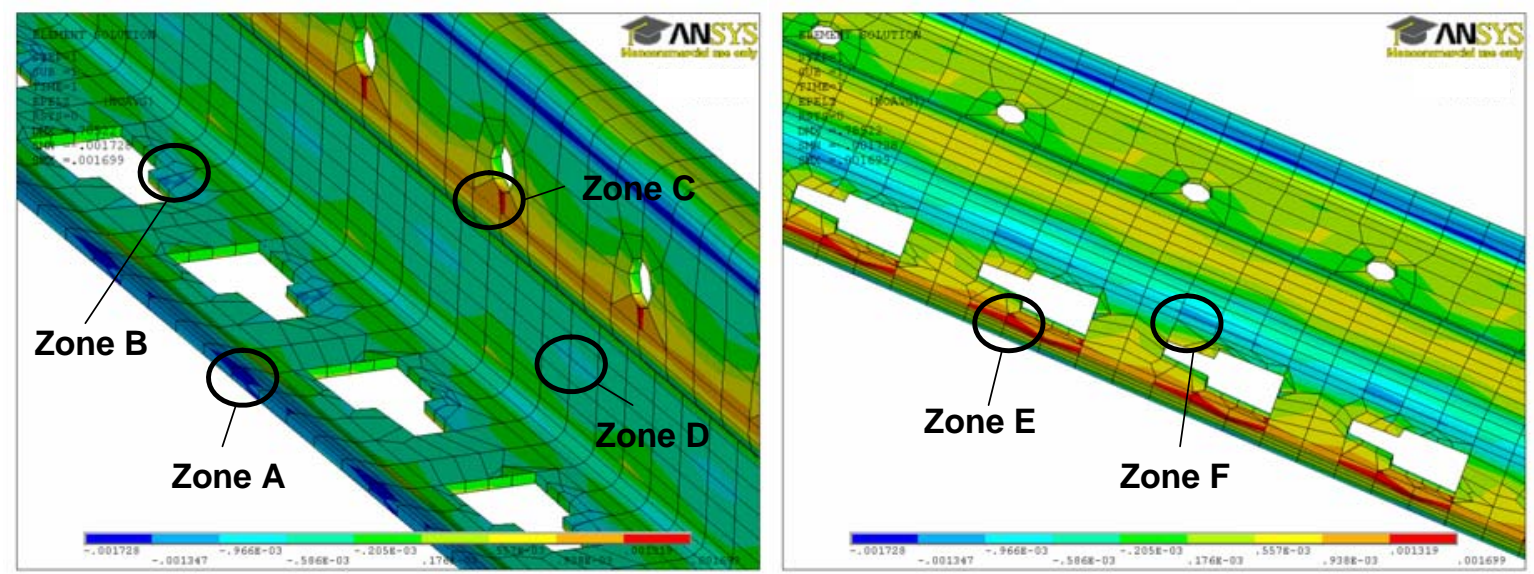

Figure 12 - Local effects in the residual longitudinal strain distribution obtained in ANSYS simulation once the data transfer is done 


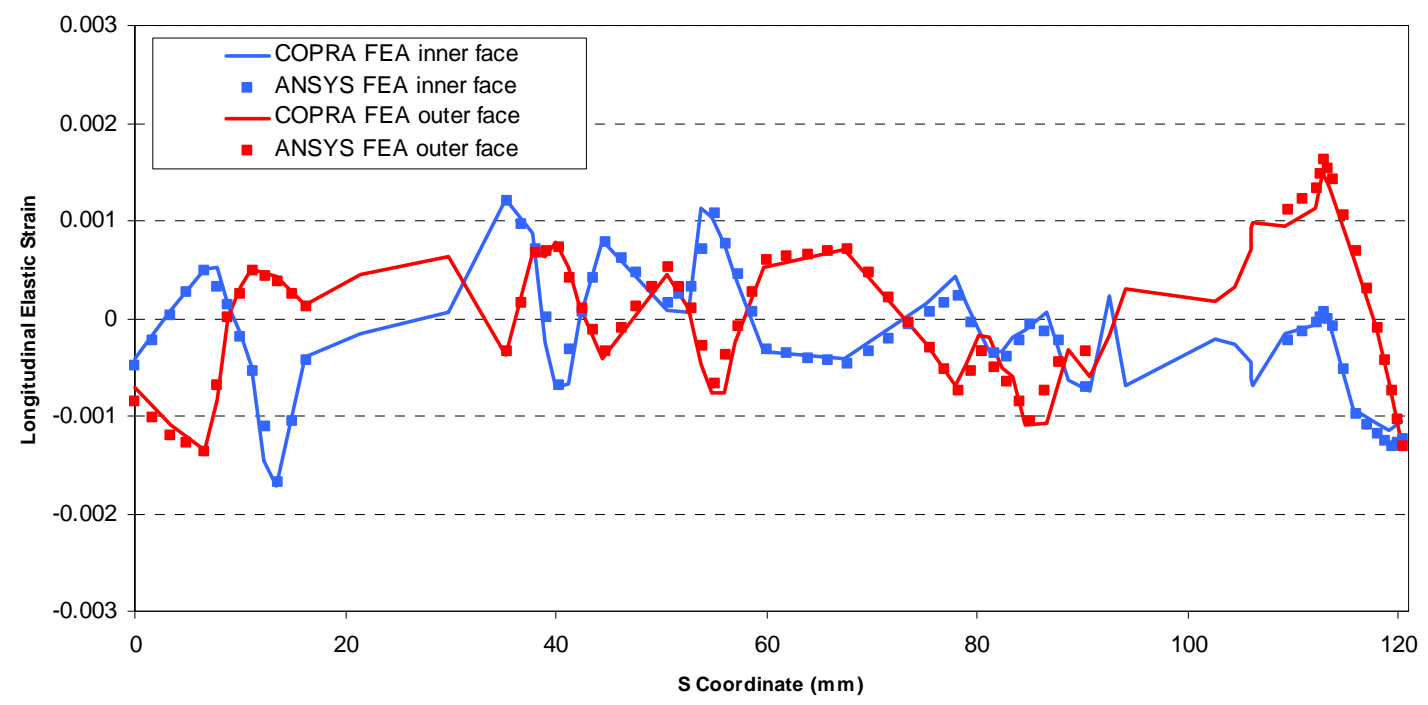

Figure 13 - Validation of the data transfer process for the longitudinal elastic residual strain at Z1

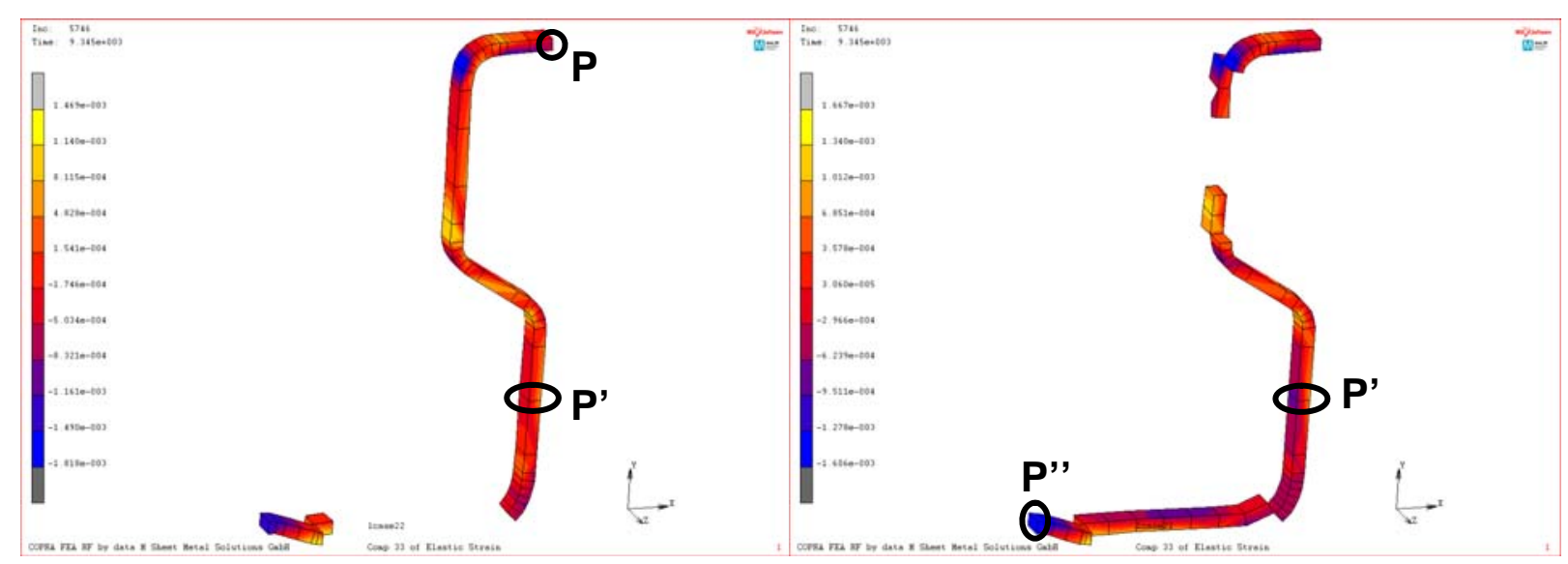

Figure 14 - Definition of the virtual path

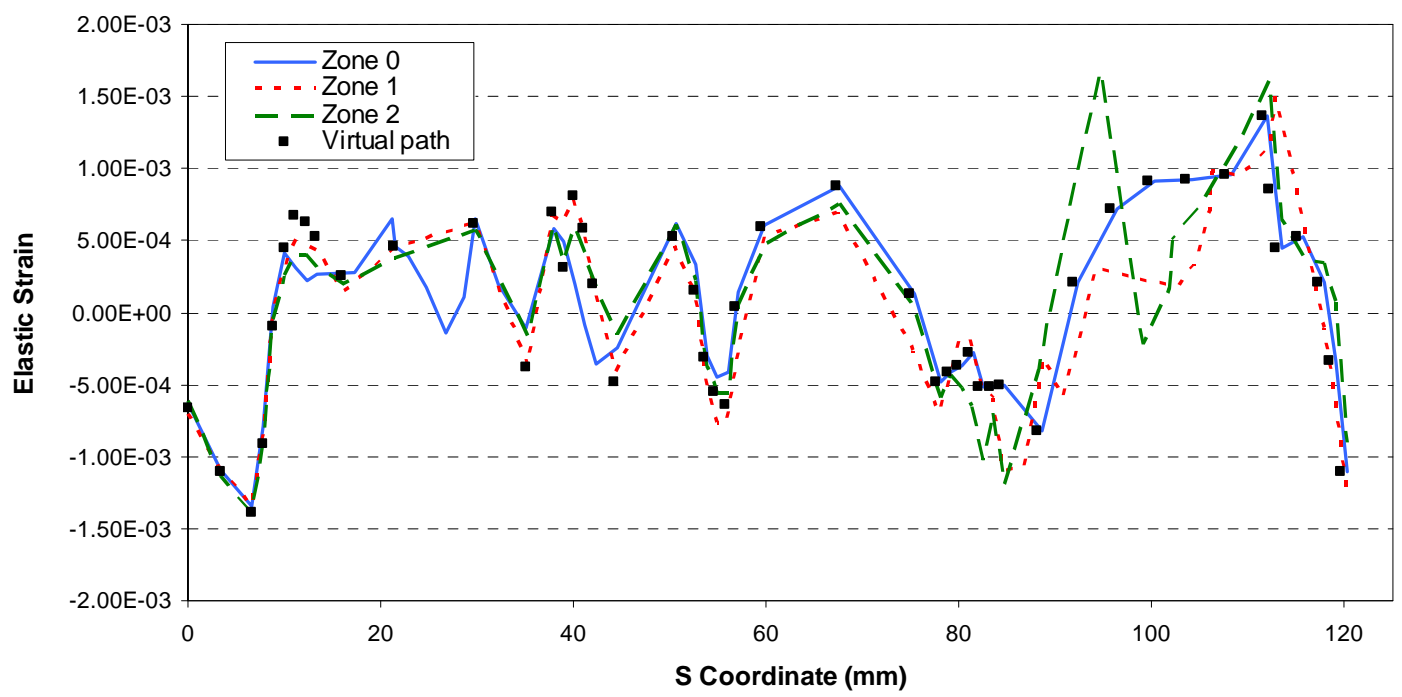

Figure 15 - Longitudinal elastic residual strains in outer face for the multi-pattern and virtual pattern methodology 

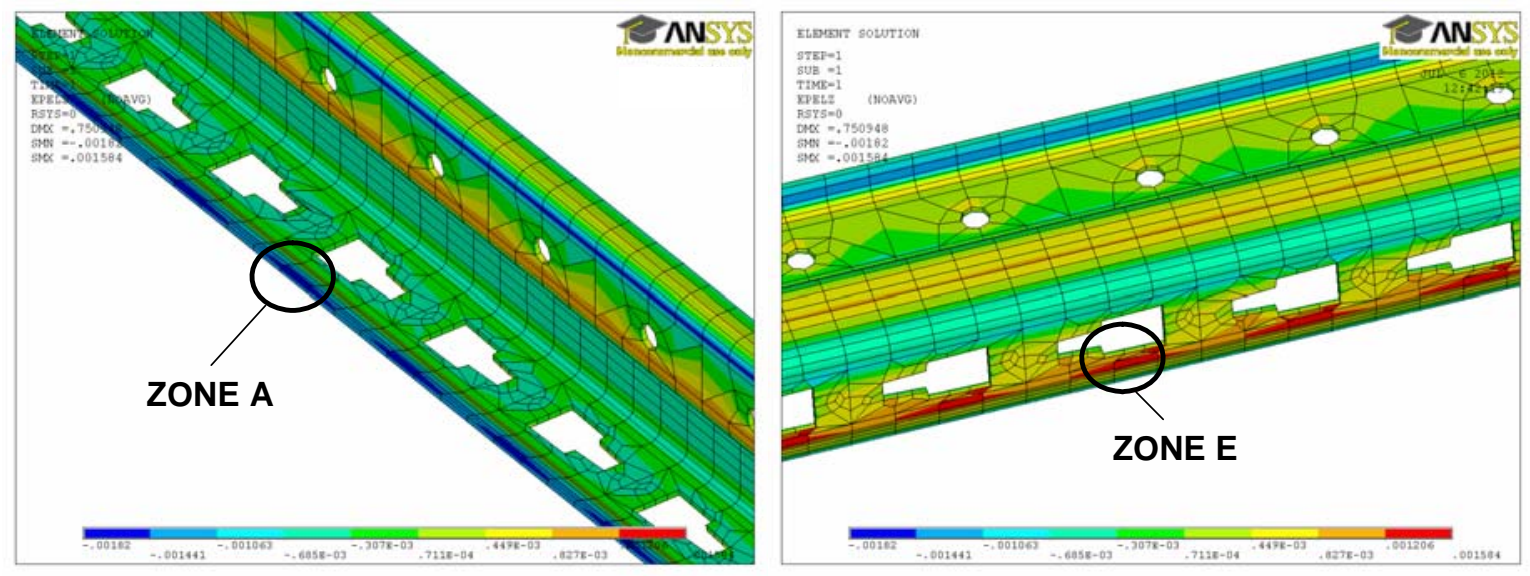

Figure 16 - Local effects reproduced by the virtual pattern methodology in ANSYS model

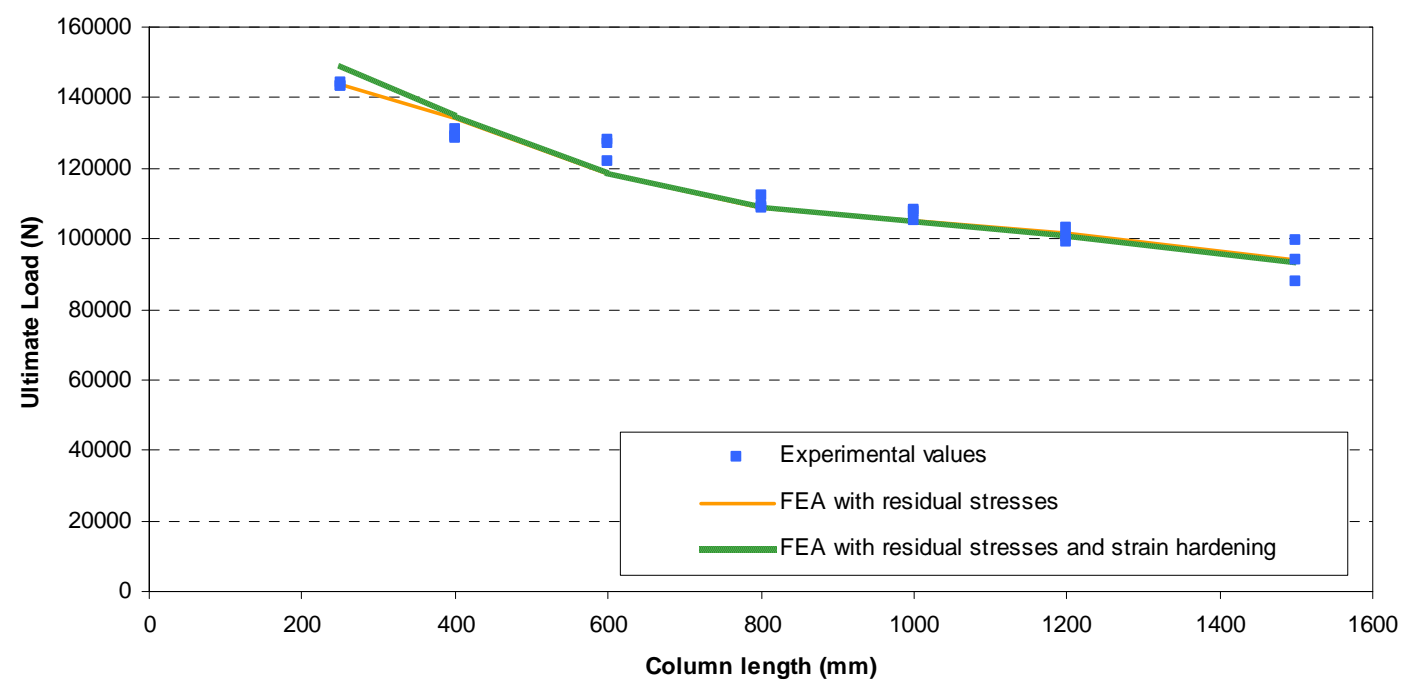

Figure 17 - Influence of strain hardening in the prediction of the ultimate load

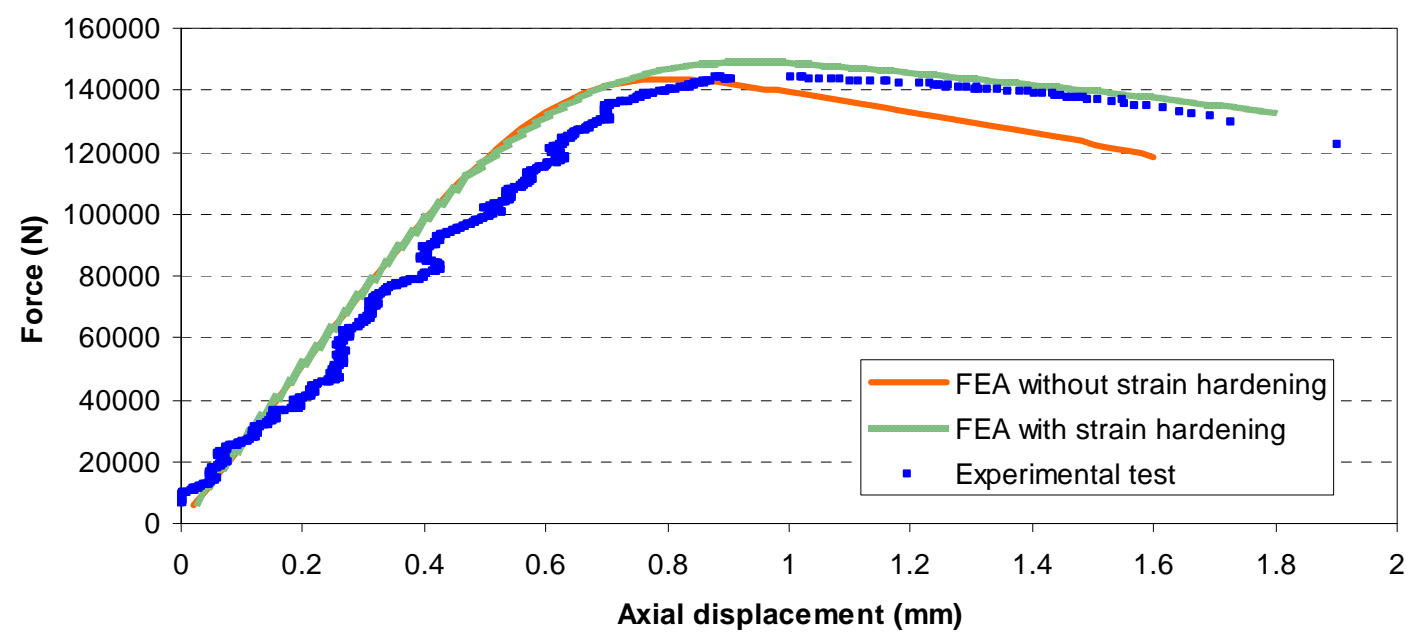

Figure 18 - Influence of the strain hardening in the post-buckling behaviour of $250 \mathrm{~mm}$ column length 
Table 1

Experimental yield and ultimate strength of the virgin sheet coil and the flat coupons (engineering values)

\begin{tabular}{cccc}
\hline Sample & Location & $\left.\mathbf{f}_{\mathbf{y}} \mathbf{( M P a}\right)$ & $\mathbf{f}_{\mathbf{u}}(\mathbf{M P a})$ \\
\hline 1 & Sheet coil & 424 & 486 \\
2 & Sheet coil & 429 & 493 \\
3 & Sheet coil & 428 & 495 \\
4 & Sheet coil & 435 & 498 \\
5 & Sheet coil & 433 & 496 \\
6 & Web & 422 & 494 \\
7 & Web & 423 & 482 \\
8 & Web & 428 & 493 \\
9 & Flange 1 & 434 & 491 \\
10 & Flange 1 & 430 & 495 \\
11 & Flange 1 & 415 & 479 \\
12 & Flange 2 & 430 & 503 \\
13 & Flange 2 & 428 & 498 \\
14 & Flange 2 & 417 & 491 \\
\hline
\end{tabular}

Table 2

Yield and ultimate strength of the flat and the corner coupons (engineering values)

\begin{tabular}{|c|c|c|}
\hline Sample & $\mathrm{f}_{\mathrm{y}}(\mathrm{MPa})$ & $\mathrm{f}_{\mathrm{u}}$ (MPa) \\
\hline Flat 1 & 417 & 478 \\
\hline Flat 2 & 416 & 483 \\
\hline Flat 3 & 422 & 479 \\
\hline Flat (Mean) & 418 & 480 \\
\hline Corner 1 & 486 & 506 \\
\hline Corner 2 & 500 & 527 \\
\hline Corner 3 & 510 & 521 \\
\hline Corner 4 & 477 & 510 \\
\hline Corner 5 & 478 & 510 \\
\hline Corner 6 & 492 & 530 \\
\hline Corner (Mean) & $491(\Delta 17.5 \%)$ & $517(\Delta 7.7 \%)$ \\
\hline
\end{tabular}

Table 3

Comparison of the different methods to obtain the yield strength of corner areas Experimental mean $\quad$ EC3-Part1-3 $\quad$ AISI S100-2007

$\begin{array}{lllll}\mathrm{f}_{\mathrm{y}, \text { corner }}(\mathrm{MPa}) & 491 & 512 & 516 & 501\end{array}$


Table 4

Results obtained by the multi-pattern methodology

\begin{tabular}{|c|c|c|c|c|c|c|c|}
\hline \multirow{2}{*}{$\begin{array}{l}\text { Column } \\
\text { length } \\
(\mathrm{mm})\end{array}$} & \multicolumn{4}{|c|}{ Experimental ultimate load (N) } & \multicolumn{2}{|c|}{ Multi-pattern FEA } & \multirow[t]{2}{*}{ FEA/EXP } \\
\hline & Sample 1 & Sample 2 & Sample 3 & Average & $\begin{array}{l}\text { Ultimate } \\
\text { load (N) }\end{array}$ & $\begin{array}{l}\text { Geometrical } \\
\text { imperfection } \\
(\mathrm{mm})\end{array}$ & \\
\hline 250 & 143461 & 144265 & 144265 & 143732 & 143814 & 0,09 & 1,00 \\
\hline 400 & 128354 & 130806 & 129060 & 129406 & 133665 & 0,11 & 1,03 \\
\hline 600 & 121683 & 127883 & 126882 & 125482 & 118308 & 0,21 & 0,94 \\
\hline 800 & 108567 & 112040 & 109293 & 109966 & 108515 & 0,5 & 0,99 \\
\hline 1000 & 104898 & 108420 & 107605 & 106974 & 104850 & 0,78 & 0,98 \\
\hline 1200 & 100326 & 102985 & 99218 & 100326 & 101635 & 0,97 & 1,01 \\
\hline 1500 & 87858 & 94107 & 99591 & 93852 & 94182 & 1,1 & 1,00 \\
\hline & & & & & & $\begin{array}{l}\text { Average } \\
\text { Deviation }\end{array}$ & $\begin{array}{l}0,99 \\
0,028\end{array}$ \\
\hline
\end{tabular}

Table 5

Results obtained by the virtual pattern methodology

\begin{tabular}{|c|c|c|c|c|c|c|c|}
\hline \multirow{2}{*}{$\begin{array}{l}\text { Column } \\
\text { length } \\
(\mathrm{mm})\end{array}$} & \multicolumn{4}{|c|}{ Experimental ultimate load (N) } & \multicolumn{2}{|c|}{ Virtual pattern FEA } & \multirow[t]{2}{*}{ FEA/EXP } \\
\hline & Sample 1 & Sample 2 & Sample 3 & Average & $\begin{array}{l}\text { Ultimate } \\
\text { load (N) }\end{array}$ & $\begin{array}{l}\text { Geometrical } \\
\text { imperfection } \\
(\mathrm{mm})\end{array}$ & \\
\hline 250 & 143461 & 144265 & 144265 & 143732 & 143599 & 0,11 & 1,00 \\
\hline 400 & 128354 & 130806 & 129060 & 129406 & 133967 & 0,13 & 1,04 \\
\hline 600 & 121683 & 127883 & 126882 & 125482 & 118139 & 0,16 & 0,94 \\
\hline 800 & 108567 & 112040 & 109293 & 109966 & 108488 & 0,41 & 0,99 \\
\hline 1000 & 104898 & 108420 & 107605 & 106974 & 104912 & 0,63 & 0,98 \\
\hline 1200 & 100326 & 102985 & 99218 & 100326 & 101398 & 0,75 & 1,01 \\
\hline 1500 & 87858 & 94107 & 99591 & 93852 & 94126 & 0,85 & 1,00 \\
\hline & & & & & & $\begin{array}{l}\text { Average } \\
\text { Deviation }\end{array}$ & $\begin{array}{l}0,99 \\
0,029\end{array}$ \\
\hline
\end{tabular}

